Journal of Animal and Veterinary Advances 18(4): 98-107, 2019

ISSN: $1680-5593$

(C) Medwell Journals, 2019

\title{
Characterization of the South American Fur Seal (Arctocephalus australis) Electrocardiogram
}

\author{
${ }^{1}$ Mariela Dassis, ${ }^{2}$ Alejandro Diaz, ${ }^{1}$ Carolina De Leon, ${ }^{1}$ Diego H. Rodriguez, ${ }^{3}$ Edgardo Rodriguez, \\ ${ }^{4}$ Alberto Ponce de Leon and ${ }^{5}$ Eduardo Castro \\ ${ }^{1}$ Instituto de Investigaciones Marinas y Costeras, Consejo Nacional de Investigaciones \\ Cientificas y Tecnicas (CONICET), Facultad de Ciencias Exactas y Naturales, \\ Universidad Nacional de Mar del Plata (UNMdP), 4046 Rodriguez Pena, \\ Nivel 1 (7600) Mar del Plata, Argentina \\ ${ }^{2}$ Instituto de Investigacion en Ciencias de las Salud, \\ Universidad Nacional del Centro de la Provincia de Buenos Aires, CONICET, \\ Pje. Arroyo Seco, S/N (7000) Tandil, Argentina \\ ${ }^{3}$ Departamento de Sanidad Animal y Medicina Preventiva, Facultad de Ciencias Veterinarias, \\ Universidad Nacional del Centro de la Provincia de Bs As, CONICET-Unidad Ejecutora CIVETAN, \\ Ciencias Veterinarias de Tandil. Pje. Arroyo Seco, S/N 7000 Tandil, Argentina \\ ${ }^{4}$ Departamento de Mamíferos Marinos, Dirección Nacional de Recursos Acuaticos (DINARA), \\ Ministerio de Ganadería, Agricultura y Pesca, 1497 Constituyente, \\ C.P. 11200 Montevideo, Uruguay \\ ${ }^{5}$ Departamento de Fisiopatologia, Facultad de Ciencias Veterinarias, \\ Universidad Nacional del Centro de la Provincia de Bs. As, \\ CONICET-Unidad Ejecutora CIVETAN, Ciencias Veterinarias de Tandil. Pje. \\ Arroyo Seco, S/N 7000 Tandil, Argentina \\ marieladassis@gmail.com, +549-223-5760682
}

\begin{abstract}
The goal of this study was to characterize the Electrocardiogram (ECG) of anesthetized South American Fur Seals (SAFS). Nineteen wild SAFS females were anesthetized with isofluorane at Isla de Lobos (Uruguay). ECG recording was performed at ventral recumbence following standardized procedures. All animals showed normal sinus rhythm. Amplitude and duration of P and T waves, QRS complex, PR interval (PRi), QT interval (QTi) and ST segment (STs) were determined. QT corrected (QTc) was determined in lead II. P wave polarity was consistent among animals (positive in LI, LII, LIII and AVF and negative in AVL and AVR). T wave polarity was consistent among animals only in LI (positive) but without a constant pattern in the others leads. The PRi $(0.128 \pm 0.009 \mathrm{sec})$ was highly similar to the allometric prediction $(0.130 \pm 0.004 \mathrm{sec})$ for most of mammalian species. Mean eupneic Heart Rate $(\mathrm{HR})$ was $118.95 \pm 18.23 \mathrm{bpm}(\mathrm{range}=100-160)$ and also similar to the allometric prediction $(111.58 \pm 2.79 \mathrm{bpm})$. The STs were normal in 17 of the SAFS but showed STs depression in 2 animals. Most of the animals $(58.9 \%)$ had a negative electrical axis. This study constituted the first detailed description of the SAFS ECG.
\end{abstract}

Key words: Electrocardiography, pinnipeds, isofluorane anaesthesia, dive physiology, ST segment, Heart Rate (HR)

\section{INTRODUCTION}

The mammalian heart has very conservative structural and functional characteristics which contrast with the evolutionary changes recorded in other anatomical structures (Meijler, 1985; Noujaim et al., 2004; Meijler and Meijler, 2011). From mouse to whale, all hearts show similar structural and functional characteristics

Corresponding Author: Mariela Dassis, Instituto de Investigaciones Marinas y Costeras, Consejo Nacional de Investigaciones Cientificas y Tecnicas (CONICET), Facultad de Ciencias Exactas y Naturales, Universidad Nacional de Mar del Plata (UNMdP), 4046 Rodriguez Pena, Nivel 1 (7600) Mar del Plata, Argentina, marieladassis@gmail.com, $+549-223-5760682$ 
(Noujaim et al., 2004; Meijler and Meijler 2011). However, diving mammals are adapted to long interruptions in breathing and have shown an extreme ability to cardiac regulation not observed in their terrestrial counterparts (Davis, 2014; Williams et al., 2015). This last includes an interplay between different degrees of tachycardia and bradycardia and a high incidence of cardiac arrhythmias that can be considered as a normal occurrence during deep dives (Williams et al., 2015).

Electrocardiography is widely used as a method to study cardiac physiology and also as a diagnostic tool for heart diseases in both, human and veterinary medicine. However, its use with aquatic mammals has been very limited and includes only 6 pinnipeds (Murdaugh et al., 1961; Van Citters et al., 1965; Ponganis et al., 1997; Andrews et al., 1997; Ponganis and Kooyman, 1999; Falabella et al., 1999; Dassis et al., 2016), two manatees (Siegal-Willott et al., 2006) and seven Cetaceans species (King et al., 1953; Senft and Kanwisher, 1960; Meijler and Van der Tweel, 1986; Kastelein and Meijler, 1989; Meijler et al., 1992; Williams et al., 1993; Ponganis and Kooyman, 1999; Harms et al., 2013). In addition, most of these studies have been conducted on captive animals or using harpoon lead electrodes which is manly related to the logistical challenge of working with marine mammals in the wild.

The ECG recording in free ranging animals using less invasive techniques has become possible only recently with the use of water proof heart rate/ECG recorders attached to wild animals (Noren et al., 2004; Davis and Williams, 2012; Davis, 2014; Williams et al., 2015). Despite this is increasing the number of species studied and highly improving the quality of information obtained these instruments use only two leads and do not enable the precise description of the typical four limb-leads ECG tracing that would help to infer and understand the cardiac bioelectricity and biomechanics subjacent to the extreme cardiac abilities of marine mammals.

The South American Fur Seal (SAFS, Arctocephalus australis) is relatively small pinniped species with an insular distribution that extends along the coast of South America from Southern Brazil to Central PerU (Vaz-Ferreira, 1982). The studies that describe in detail the cardiac anatomy of SAFS emphasize that the heart is structurally similar to other mammals with morphological changes that assist in their adaptation to their aquatic environment (Perez et al., 2008; Guimaraes et al., 2014). Briefly, the SAFS heart is flat, elongated and positioned on the left side of median line in the thoracic cavity between 3rd and 7th ribs (Perez et al., 2008). As no previous values of ECG have been reported for this species, the main objective of this study was to characterize the electrocardiogram of anaesthetized SAFS and to determine temporal and amplitude values for all waves, intervals and segments. The information obtained here represented valuable information for comparative electrophysiology analysis in relation to other aquatic and terrestrial mammals, including humans. In this sense, result regarding to heart rate and AV (Atrio-Ventricular) conduction time were discussed in terms of allometric predictions for most of mammalian species.

\section{MATERIALS AND METHODS}

This research was performed during May 2013 on Isla de Lobos ( $35^{\circ} 01^{\prime} \mathrm{S} 54^{\circ} 52^{\prime} \mathrm{W}$; Uruguay). Animal capture and handling was performed by personnel of the Uruguayan Government (Direccion Nacional de Recursos Acuaticos de Uruguay, DINARA) following local and international ethic regulations for manipulation of wild animals (experimental protocols were approved by Universidad Nacional de Mar de Plata Institutional Animal Care and Use Committee, CICUAL; Resolution 137/15). Fur seals from this study were used to deploy telemetry devices for foraging behaviour studies (Carman et al., 2016).

Nineteen wild SAFS females (Table 1) were live captured and held in a corral under veterinary observation for $24 \mathrm{~h}$. Animals were physically restrained using a squeeze cage and anesthetized with isoflurane using a mask and later with an endotracheal tube. All physical signs, including head movement, jaw tone, palpebral reflex, eye position, iris appearance, respiratory character and capillary refill were monitored from the time of first approach. After intubation, these physical signs plus the electronic readings (veterinary monitor Guoteng) were monitored constantly by the anesthetist and recorded at $10 \mathrm{~min}$ intervals. Details of animal's manipulation and anaesthesia procedures were similar to those applied by the researchers on a previous study with Southern Sea Lion (SSL) females (Dassis et al., 2016).

Table 1: Morphometric measurements of South American fur seals females anesthetized for ECG recording

\begin{tabular}{lccc}
\hline Animals & $\begin{array}{l}\text { Body mass } \\
(\mathrm{kg})\end{array}$ & $\begin{array}{l}\text { Total length } \\
(\mathrm{cm})\end{array}$ & $\begin{array}{l}\text { Curve length } \\
(\mathrm{cm})\end{array}$ \\
\hline 1 & 46.0 & 135.0 & 137.0 \\
2 & 46.5 & 128.0 & 136.0 \\
3 & 48.5 & 126.0 & 131.0 \\
4 & 40.0 & 124.0 & 130.0 \\
5 & 37.0 & 125.0 & 128.0 \\
6 & 48.8 & 133.0 & 140.0 \\
7 & 41.4 & 128.0 & 133.0 \\
8 & 34.8 & 125.0 & 127.0 \\
9 & 34.9 & 120.0 & 124.0 \\
10 & 42.1 & 131.0 & 133.0 \\
11 & 39.8 & 135.0 & 138.0 \\
12 & 47.8 & 133.0 & 137.0 \\
13 & 44.2 & 132.0 & 136.0 \\
14 & 37.2 & 132.0 & 136.0 \\
15 & 39.8 & 136.0 & 140.0 \\
16 & 49.9 & 133.0 & 135.0 \\
17 & 40.3 & 137.0 & 140.0 \\
18 & 42.4 & 133.0 & 137.0 \\
19 & 32.8 & 118.0 & 119.0 \\
\hline Mean: $41.8,129.7,133.5 ;$ SD: $5.1,5.4,5.8 ;$ Coef. var: $12.3,4.2,4.3$
\end{tabular}


ECG recordings were performed in ventral recumbence with standard bipolar and unipolar limb leads (LI, LII, LIII, AVR, AVL and AVF) (Bolton, 1975; Detweiler, 1988; Tilley and Tilley, 1992; Kligfield et al., 2007). ECG recordings were performed $30 \mathrm{~min}$ after intubation when animals reached a stable and profound anaesthetic stage. Limb leads were secured to the lateral aspect of the body wall using clip electrode as follows: the left and right forelimb leads were placed $3-5 \mathrm{~cm}$ cranial to the pectoral flippers insertion, approximately at the level of the scapular girth. The left and right hind leads were placed $3-5 \mathrm{~cm}$ cranial to the pelvic flippers insertion, approximately at the level of the pelvic girth.

Clip electrodes were manufactured in an appropriated size to clip fur seals peel $(3.5 \mathrm{~cm}$ length, $1 \mathrm{~cm}$ opening width). Skin areas of electrode attachment were wetted with alcohol. ECGs were recorded using the portable device RG-401 Plus (Cardiotencia S.R.L, Argentina). The recording speed was $50 \mathrm{~mm} / \mathrm{sec}$ and the sensitivity set at $1 \mathrm{~cm}=1 \mathrm{mV}$, using a $45 \mathrm{~mm}$-wide paper. No filter was used during any recording. LII was additionally recorded at 25 $\mathrm{mm} / \mathrm{sec}$ to determinate Heart Rate (HR).

Amplitude in millivolts $(\mathrm{mV})$ and duration in seconds (sec) of P and T waves, QRS complex, PRi, QTi and STs were measured as defined in standard clinical usage (Bolton 1975; Tilley and Tilley 1992; Anonymous, 2010). Each measurement for each wave, complex, interval or segment was performed six times in every lead in each animal. All measurements were made manually using a calliper following standard clinical usage (Bolton 1975; Tilley and Smith, 2008; Detweiler, 1988; Tilley and Tilley, 1992).

The PRi was measured from the beginning of the $P$ wave to the beginning of the QRS complex and compared to a predicted value estimated from fur seals Body Mass (BM) and the allometric equation proposed by Noujaim et al. (2004). Predicted PRi $=53 \times \mathrm{BM}^{0.24}$. HR in bpm (beats per min) was estimated from the LII recorded at $25 \mathrm{~mm} / \mathrm{sec}$ (small boxes between consecutive $\mathrm{R}$ waves divided by 3000 ). Similar to PRi this value was compared to a predicted value estimated from fur seals BM and the allometric equation proposed by Noujaim et al. (2004) predicted $\mathrm{HR}=235 \times \mathrm{BM}^{-0.2}$.

The QTi was measured from the beginning of the $Q$ wave to the end of the T wave. QTi was corrected (QTc) for heart rate using Bazett's formula (Bazett, 1920). The STs was measured between the end of the S wave and the beginning of the T wave. Following Bolton (1975) the ST was considered abnormal when it displayed more than $0.2 \mathrm{mV}$ below the baseline an occurrence referred to as ST depression. The mean electrical axis was determined using the isoelectric method by examining the QRS complexes in each of the six basic leads following standard procedure (Bolton, 1975; Tilley and Tilley, 1992). Mean ( $\bar{x})$, Standard Deviation (SD), Coefficient of Variation (CV) and 95\% confidence intervals were calculated for each measurement in every lead. Statistic analyses were performed using PROC MEANS y PROC TTEST procedures of the Statistic Software SAS V9.2 (SAS Software, 2011 ).

\section{RESULTS AND DISCUSSION}

ECG recordings showed normal sinus rhythm in all animals (Fig. 1). Wave amplitudes were highly consistent for each animal in every lead. $\mathrm{P}$ wave polarity was consistent among animals (positive in LI, LII, LIII and AVF leads and negative in AVL and AVR leads for all animals (Table 2, Fig. 1). One animal also presented an unusual notched $\mathrm{P}$ wave in LII (Fig. 2). T wave polarity was consistent among animals only in LI (always positive) but did not present any constant pattern in the rest of the leads, being either positive, negative or biphasic (Table 2).

The PRi ranged from $0.111 \pm 0.003$ to $0.149 \pm 0.002 \mathrm{sec}$ in animals 8 and 12 , respectively with an overall mean value of $0.128 \pm 0.009 \mathrm{sec}$ for all animals (measured PRi; Table 3). The predicted PRi was highly concordant $(0.130 \pm 0.004 \mathrm{sec})$ with minimal differences ranging from 0 (complete concordance between measured and predicted PRi) to a maximum of $0.02 \mathrm{sec}$. (average difference $=0.008 \pm 0.006 \mathrm{sec}$ ). An inverse correlation was observed between PRi and HR ( $\left.\mathrm{r}^{2}: 0.64\right)$. Mean eupneic HR for anesthetized animals $(\mathrm{n}=19)$ was $118.95 \pm 18.23 \mathrm{bpm}$, ranging from 100-160 bpm (Table 3). Predicted HR (111.58 $\pm 2.79 \mathrm{bpm}$ ) was also similar to the measured value (Table 3 ) with differences ranging from $5-50 \mathrm{bpm}$ (average difference $=16.34 \pm 10.95 \mathrm{bpm}$ ).

Amplitude of $\mathrm{P}-\mathrm{T}$ waves and duration of $\mathrm{P}, \mathrm{T}$ waves, QRS complex, QT interval and ST segment are summarized in Table 4 and 5, respectively. QTc was $0.365 \pm 0.037$ and the difference with QTi $(0.261 \pm 0.028)$ was significant $(\mathrm{t}=$ $-17.86, \mathrm{p}<0.0001$ ). The STs were normal (no evident depression) in most of the fur seals studied $(n=17)$. However, 2 exceptions were observed. Animals 2 and 15 showed STs depression in LII (Fig. 3). Most of animals $(58.9 \%)$ had a negative electrical axis ranging between -90 and $-120^{\circ}$ with the rest of the animals $(41.1 \%)$ with a positive electrical axis (between 30 and $120^{\circ}$ ).

The present study provides the first detailed description of the anaesthetized SAFS electrocardiogram. The ECG pattern resembled, in its essential details, the ECG tracing of terrestrial and marine mammals (Meijler and 

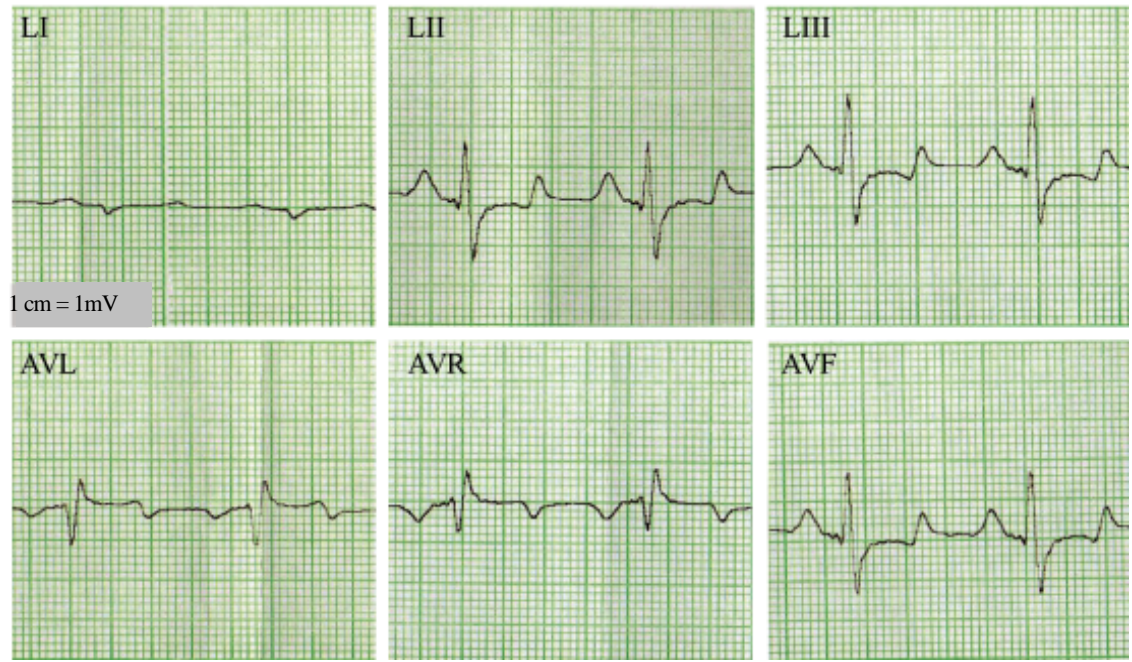

Fig. 1: Typical ECG tracing in one anesthetized South American fur seals female

$\underline{\text { Table 2: Polarities of } \mathrm{P} \text { (left) and } \mathrm{T} \text { (right) waves in ECG recordings of South American fur seals females }}$

\begin{tabular}{|c|c|c|c|c|c|c|c|c|c|c|c|c|}
\hline \multirow[b]{2}{*}{ Animals } & \multicolumn{5}{|c|}{$\mathrm{P}$ wave polarity } & \multicolumn{7}{|c|}{$\mathrm{T}$ wave polarity } \\
\hline & LI & LII & LIII & AVR & AVL & AVF & LI & LII & LIII & AVR & AVL & AVF \\
\hline 1 & + & + & + & - & - & + & nd & + & + & - & - & + \\
\hline 2 & + & + & + & - & - & + & + & + & + & - & - & + \\
\hline 3 & + & + & + & - & - & nd & + & \pm & \pm & \pm & \pm & nd \\
\hline 4 & + & + & + & - & - & + & + & \pm & \pm & \pm & \pm & \pm \\
\hline 5 & + & + & + & - & - & + & nd & - & - & + & + & - \\
\hline 6 & + & + & + & - & - & + & + & + & + & - & - & + \\
\hline 7 & + & + & + & - & - & + & nd & + & + & - & - & + \\
\hline 8 & + & + & + & - & - & + & + & + & + & - & \pm & + \\
\hline 9 & + & + & + & - & - & + & + & + & + & - & - & + \\
\hline 10 & + & + & + & - & - & + & + & + & + & - & - & + \\
\hline 11 & + & + & + & - & - & + & + & + & \pm & - & \pm & + \\
\hline 12 & + & + & + & - & - & + & + & + & + & - & - & + \\
\hline 13 & nd & + & + & - & - & + & + & \pm & \pm & - & + & \pm \\
\hline 14 & + & + & + & - & - & + & nd & \pm & \pm & \pm & \pm & \pm \\
\hline 15 & + & + & + & - & - & + & + & \pm & - & \pm & + & - \\
\hline 16 & + & + & + & - & - & + & + & + & + & - & - & + \\
\hline 17 & + & + & + & - & - & + & + & + & + & - & \pm & + \\
\hline 18 & + & + & + & - & - & + & + & + & + & - & - & + \\
\hline 19 & + & + & + & - & - & + & + & + & + & - & - & + \\
\hline
\end{tabular}

$\mathrm{ND}=$ No Data, $( \pm)=$ Isolectric deflection

Table 3: Heart Rate (HR in bpm) and PR interval of each lead (PRi in sec) in South American fur seals ECGs $(N=19)$, respectively, compared to predicted $\mathrm{HR}$ and PRi according to body mass and Noujaim et al. (2004) equations

\begin{tabular}{|c|c|c|c|c|c|c|c|c|c|c|c|}
\hline Animals & $\begin{array}{l}\text { Body mass } \\
(\mathrm{kg})\end{array}$ & $\mathrm{LI}$ & LII & LIII & AVR & AVL & AVF & $\begin{array}{l}\text { Measured PRI } \\
(\text { mean } \pm \text { SD) }\end{array}$ & $\begin{array}{l}\text { Predicted } \\
\text { (PRI) }\end{array}$ & $\begin{array}{l}\text { Measured } \\
(\mathrm{HR})\end{array}$ & $\begin{array}{l}\text { Predicted } \\
(\mathrm{HR})\end{array}$ \\
\hline 1 & 46.0 & nd & 0.12 & 0.12 & 0.11 & 0.12 & 0.12 & $0.114 \pm 0.003$ & 0.133 & 160 & 109.3 \\
\hline 2 & 46.5 & 0.11 & 0.13 & 0.13 & 0.13 & 0.11 & 0.13 & $0.122 \pm 0.009$ & 0.133 & 140 & 109.0 \\
\hline 3 & 48.5 & 0.13 & 0.12 & 0.12 & 0.13 & 0.13 & nd & $0.125 \pm 0.005$ & 0.135 & 120 & 108.1 \\
\hline 4 & 40.0 & nd & 0.14 & 0.13 & 0.13 & 0.12 & 0.13 & $0.130 \pm 0.005$ & 0.128 & 120 & 112.4 \\
\hline 5 & 37.0 & nd & 0.13 & 0.12 & 0.13 & 0.13 & 0.12 & $0.126 \pm 0.005$ & 0.126 & 120 & 114.1 \\
\hline 6 & 48.8 & 0.12 & 0.12 & 0.12 & 0.12 & 0.12 & 0.12 & $0.120 \pm 0.004$ & 0.135 & 120 & 108.0 \\
\hline 7 & 41.4 & nd & 0.13 & 0.12 & 0.13 & 0.12 & 0.12 & $0.124 \pm 0.002$ & 0.130 & 140 & 111.6 \\
\hline 8 & 34.8 & 0.11 & 0.11 & 0.11 & 0.12 & 0.11 & 0.11 & $0.111 \pm 0.003$ & 0.124 & 140 & 115.5 \\
\hline 9 & 34.9 & 0.14 & 0.14 & 0.14 & 0.14 & 0.14 & 0.14 & $0.141 \pm 0.003$ & 0.124 & 100 & 115.5 \\
\hline 10 & 42.1 & 0.13 & 0.13 & 0.13 & 0.14 & 0.13 & 0.13 & $0.131 \pm 0.004$ & 0.130 & 120 & 111.2 \\
\hline 11 & 39.8 & 0.15 & 0.12 & 0.12 & 0.13 & 0.12 & 0.13 & $0.130 \pm 0.010$ & 0.128 & 100 & 112.5 \\
\hline 12 & 47.8 & nd & 0.15 & 0.15 & 0.15 & 0.15 & 0.15 & $0.149 \pm 0.002$ & 0.134 & 100 & 108.4 \\
\hline 13 & 44.2 & nd & 0.13 & 0.12 & 0.13 & 0.13 & 0.13 & $0.127 \pm 0.003$ & 0.132 & 100 & 110.1 \\
\hline
\end{tabular}




\begin{tabular}{|c|c|c|c|c|c|c|c|c|c|c|c|}
\hline Animals & $\begin{array}{l}\text { Body mass } \\
(\mathrm{kg})\end{array}$ & $\mathrm{LI}$ & LII & LIII & AVR & AVL & AVF & $\begin{array}{l}\text { Measured PRI } \\
\text { (mean } \pm \text { SD) }\end{array}$ & $\begin{array}{l}\text { Predicted } \\
\text { (PRI) }\end{array}$ & $\begin{array}{l}\text { Measured } \\
(\mathrm{HR})\end{array}$ & $\begin{array}{l}\text { Predicted } \\
\text { (HR) }\end{array}$ \\
\hline 14 & 37.2 & nd & 0.14 & 0.14 & 0.14 & 0.14 & 0.14 & $0.137 \pm 0.002$ & 0.126 & 100 & 114.0 \\
\hline 15 & 39.8 & nd & 0.14 & 0.13 & 0.14 & 0.12 & 0.13 & $0.133 \pm 0.006$ & 0.128 & 100 & 112.5 \\
\hline 16 & 49.9 & 0.13 & 0.12 & 0.13 & 0.14 & 0.12 & 0.12 & $0.127 \pm 0.008$ & 0.135 & 120 & 107.5 \\
\hline 17 & 40.3 & 0.14 & 0.14 & 0.13 & 0.14 & 0.13 & 0.14 & $0.137 \pm 0.006$ & 0.129 & 100 & 112.2 \\
\hline 18 & 42.4 & nd & 0.13 & 0.13 & 0.14 & 0.13 & 0.13 & $0.134 \pm 0.002$ & 0.130 & 120 & 111.1 \\
\hline$\underline{19}$ & 32.8 & 0.11 & 0.12 & 0.12 & 0.12 & 0.12 & 0.12 & $0.117 \pm 0.003$ & 0.122 & 140 & 116.9 \\
\hline
\end{tabular}

Mean: $41.8,0.128,0.130,118.95,111.58$; SD: $5.1,0.009,0.004,18.23,2.79$; Coef. var: $12.3,7.2,3.0,15.3,2.50$; ND = No Data

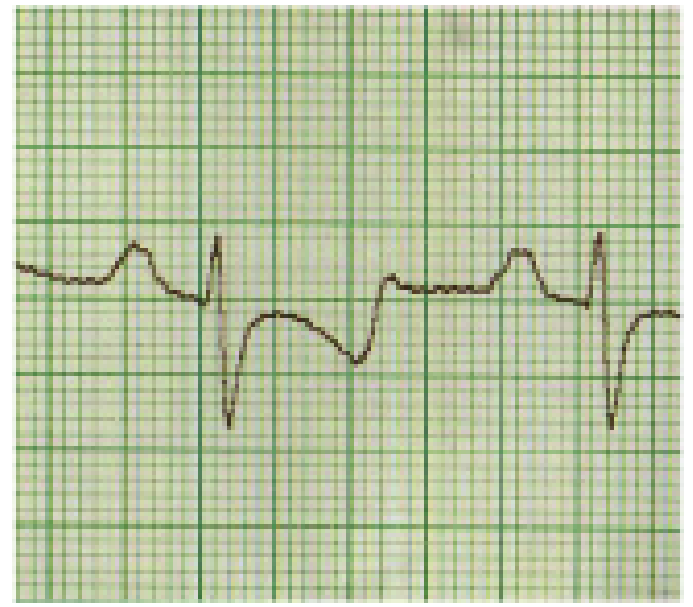

Fig. 2: ECG in LII showing a typical notched $P$ wave morphology detected in one animal from this study

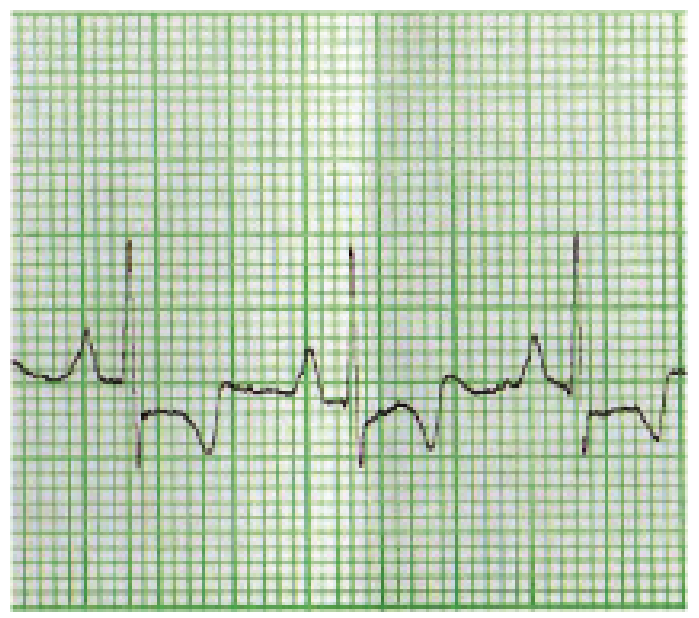

Fig. 3: ECG in LII, showing an example of the ST segment depression observed in two of the animals studied

Meijler, 2011). All the waves, intervals and segments of the ECG were identified and could be easily separated. All animals revealed normal sinus rhythm with no detectable arrhythmias. The SAFS ECG characteristically displayed distinctly defined ST segment and QT interval with a T wave clearly differentiated from the QRS complex. No polarity inversion was registered in any lead.
All animals showed P wave low voltage in LI this finding suggest that atrial cardiac vector activation runs perpendicular to LI. We observed a consistent pattern of atrial depolarization for all leads in all ECGs but 1 animal presented an unusual notched $\mathrm{P}$ wave. According the species under study this unusual $\mathrm{P}$ wave morphology could be considered a normal finding (Hamlin et al., 1970) or suggest an atrial enlargement (due to delayed interatrial depolarization) (Bolton, 1975; Tilley and Smith, 2008). Similar to our results, previous reports described an occasionally biphasic $\mathrm{P}$ wave in elephant seals, harbour seals, California Sea lions (Hamlin et al., 1972) and manatees (Siegal-Willot et al., 2006), although, their causes were not established. In this sense, studies of macroscopic anatomy on the size and structure of the atria in SAFS are scarce and show controversial data. Perez et al. (2008) reported that both atria had few pectinate muscles and that the right atrium was much smaller than the left, based on 12 specimens (Perez et al., 2008). By Guimaraes et al. (2014) studied the macroscopic characteristics of both atria in 24 SAFS specimens showing that the right atrium was larger than the left atrium.

In this study the measured HR was concordant with predicted HR (118 vs. $111 \mathrm{bpm}$, respectively) and showed a correlation with body mass (mean $41.8 \pm 5.1 \mathrm{~kg}$ ). Resting HR is known to scale inversely to body mass in terrestrial mammals, for example, HR changes from $600 \mathrm{bpm}$ in the conscious mouse (Gehrmann et al. 2000) to $30 \mathrm{bpm}$ in the humpback whale (Meijler et al. 1992). This scaling of the HR with the body mass is also observed in marine mammals. Taking as an example it is observed that large marine mammals as beluga whale (mean $1136 \mathrm{~kg}$; King et al. 1953) show an average HR of $16 \mathrm{bpm}$, however, pinnipeds with smaller body mass have higher HR with averages of 104-118 bmp ( 80 and $50 \mathrm{~kg}$ for Southern Sea Lions (Dassis et al., 2016) and SAFS, respectively. Moreover, specifically in pinnipeds, both apneic and eupneic HR declined with increasing body mass (Castellini and Zenteno-Savin, 1997).

The PRi reflects the slowed conduction through the AV node (Bolton, 1975; Tilley and Smith, 2008). The changes in the mammalian heart that did take place were mostly adjustments in order to compensate body size 
J. Anim. Vet. Adv., 18 (4): 98-107, 2019

Table 4: Amplitude measurements (mV) of each lead recorded in South American fur seals ECGs $(\mathrm{N}=19)$

\begin{tabular}{|c|c|c|c|c|c|c|}
\hline \multirow[b]{2}{*}{$\underline{\text { Wave/Lead }}$} & \multirow[b]{2}{*}{$\mathrm{n}$} & \multirow[b]{2}{*}{ Mean } & \multirow[b]{2}{*}{$\mathrm{SD}$} & \multirow[b]{2}{*}{ Coef. var. } & \multicolumn{2}{|c|}{ CL $95 \%$ for mean } \\
\hline & & & & & Lower & Upper \\
\hline \multicolumn{7}{|l|}{$\bar{P}$} \\
\hline LI & 5 & 0.0866 & 0.0083 & 21.4921 & 0.0635 & 0.1097 \\
\hline LII & 19 & 0.3209 & 0.0112 & 15.1628 & 0.2974 & 0.3443 \\
\hline LIII & 19 & 0.2794 & 0.0123 & 19.2535 & 0.2535 & 0.3053 \\
\hline AVR & 19 & 0.1952 & 0.0068 & 15.2235 & 0.1809 & 0.2095 \\
\hline AVL & 19 & 0.1201 & 0.0069 & 24.8832 & 0.1057 & 0.1345 \\
\hline AVF & 18 & 0.3018 & 0.0120 & 16.8862 & 0.2764 & 0.3271 \\
\hline \multicolumn{7}{|l|}{$Q$} \\
\hline LI & 5 & 0.0751 & 0.0155 & 45.984 & 0.0322 & 0.1180 \\
\hline LII & 16 & 0.1051 & 0.0139 & 52.8778 & 0.0755 & 0.1347 \\
\hline LIII & 12 & 0.0956 & 0.0134 & 48.6949 & 0.066 & 0.1252 \\
\hline AVR & 18 & 0.4012 & 0.0400 & 42.3136 & 0.3168 & 0.4856 \\
\hline AVL & 18 & 0.3632 & 0.0289 & 33.7039 & 0.3023 & 0.4241 \\
\hline AVF & 12 & 0.1085 & 0.0147 & 46.8518 & 0.0762 & 0.1407 \\
\hline \multicolumn{7}{|l|}{$\mathbf{R}$} \\
\hline LI & 5 & 0.1570 & 0.0183 & 26.0597 & 0.1062 & 0.2077 \\
\hline LII & 19 & 0.7381 & 0.0521 & 30.7461 & 0.6288 & 0.8475 \\
\hline LIII & 19 & 0.7077 & 0.0506 & 31.1935 & 0.6013 & 0.8141 \\
\hline AVR & 19 & 0.3824 & 0.0340 & 38.7034 & 0.3111 & 0.4537 \\
\hline AVL & 19 & 0.3362 & 0.0235 & 30.4852 & 0.2868 & 0.3856 \\
\hline AVF & 18 & 0.7462 & 0.0547 & 31.1218 & 0.6307 & 0.8616 \\
\hline \multicolumn{7}{|l|}{$\mathbf{S}$} \\
\hline LI & 5 & 0.1058 & 0.0265 & 55.9257 & 0.0323 & 0.1793 \\
\hline LII & 19 & 0.7263 & 0.0567 & 34.0429 & 0.6071 & 0.8455 \\
\hline LIII & 19 & 0.7003 & 0.0529 & 32.9042 & 0.5892 & 0.8113 \\
\hline AVR & 4 & 0.3644 & 0.1002 & 55.0001 & 0.0455 & 0.6832 \\
\hline AVL & 1 & 0.3306 & . & . & . & . \\
\hline AVF & 18 & 0.7073 & 0.0577 & 34.6004 & 0.5856 & 0.8290 \\
\hline \multicolumn{7}{|l|}{$\mathbf{T}$} \\
\hline LI & 5 & 0.1337 & 0.0197 & 33.0301 & 0.0789 & 0.1885 \\
\hline LII & 19 & 0.3876 & 0.0255 & 28.7226 & 0.3339 & 0.4412 \\
\hline LIII & 19 & 0.3498 & 0.0278 & 34.6481 & 0.2914 & 0.4082 \\
\hline AVR & 19 & 0.2373 & 0.0144 & 26.4039 & 0.2071 & 0.2676 \\
\hline AVL & 19 & 0.1656 & 0.0140 & 36.753 & 0.1363 & 0.1949 \\
\hline AVF & 18 & 0.3665 & 0.0248 & 28.7071 & 0.3142 & 0.4188 \\
\hline
\end{tabular}

Table 5: Duration measurements (sec) of each lead recorded in South American fur seals ECGs $(\mathrm{N}=19)$

\begin{tabular}{|c|c|c|c|c|c|c|}
\hline \multirow[b]{2}{*}{ Measurement/lead } & \multirow[b]{2}{*}{$\mathrm{n}$} & \multirow[b]{2}{*}{ Mean } & \multirow[b]{2}{*}{$\mathrm{SD}$} & \multirow[b]{2}{*}{ Coef. var. } & \multicolumn{2}{|c|}{ CL $95 \%$ for mean } \\
\hline & & & & & Lower & Upper \\
\hline \multicolumn{7}{|l|}{ Pwave } \\
\hline $\mathrm{LI}$ & 11 & 0.0696 & 0.0020 & 9.33660 & 0.0652 & 0.0740 \\
\hline LII & 19 & 0.0834 & 0.0013 & 6.87250 & 0.0807 & 0.0862 \\
\hline LIII & 19 & 0.0805 & 0.0017 & 9.08260 & 0.0770 & 0.0840 \\
\hline AVR & 19 & 0.0791 & 0.0015 & 8.28960 & 0.0759 & 0.0823 \\
\hline AVL & 19 & 0.0708 & 0.0017 & 10.4749 & 0.0672 & 0.0743 \\
\hline AVF & 18 & 0.0803 & 0.0013 & 6.82960 & 0.0776 & 0.0830 \\
\hline \multicolumn{7}{|l|}{ QRS complex } \\
\hline LI & 11 & 0.0594 & 0.0052 & 29.2309 & 0.0477 & 0.0710 \\
\hline LII & 19 & 0.0751 & 0.0033 & 18.8747 & 0.0683 & 0.0819 \\
\hline LIII & 19 & 0.0735 & 0.0029 & 16.9774 & 0.0675 & 0.0795 \\
\hline AVR & 19 & 0.0721 & 0.0021 & 12.4156 & 0.0678 & 0.0764 \\
\hline AVL & 19 & 0.0679 & 0.0021 & 13.4217 & 0.0636 & 0.0723 \\
\hline AVF & 18 & 0.0761 & 0.0021 & 11.8220 & 0.0716 & 0.0805 \\
\hline \multicolumn{7}{|l|}{ PR interval } \\
\hline $\mathrm{LI}$ & 10 & 0.1282 & 0.0044 & 10.8282 & 0.1182 & 0.1381 \\
\hline LII & 19 & 0.1288 & 0.0024 & 7.99490 & 0.1239 & 0.1338 \\
\hline LIII & 19 & 0.1269 & 0.0020 & 6.97970 & 0.1227 & 0.1312 \\
\hline AVR & 19 & 0.1320 & 0.0024 & 7.98480 & 0.1269 & 0.1371 \\
\hline AVL & 19 & 0.1252 & 0.0023 & 8.17660 & 0.1203 & 0.1301 \\
\hline AVF & 18 & 0.1284 & 0.0023 & 7.61090 & 0.1235 & 0.1332 \\
\hline \multicolumn{7}{|l|}{ QT interval } \\
\hline $\mathrm{LI}$ & 10 & 0.2392 & 0.0079 & 10.5098 & 0.2212 & 0.2572 \\
\hline LII & 19 & 0.2592 & 0.0061 & 10.1760 & 0.2465 & 0.2719 \\
\hline LIII & 19 & 0.2592 & 0.0054 & 9.07980 & 0.2479 & 0.2705 \\
\hline AVR & 19 & 0.2553 & 0.0055 & 9.33480 & 0.2438 & 0.2668 \\
\hline
\end{tabular}


Table 5: Continue

\begin{tabular}{|c|c|c|c|c|c|c|}
\hline \multirow[b]{2}{*}{ Measurement/lead } & \multirow[b]{2}{*}{$\mathrm{n}$} & \multirow[b]{2}{*}{ Mean } & \multirow[b]{2}{*}{ SD } & \multirow[b]{2}{*}{ Coef. var. } & \multicolumn{2}{|c|}{ CL $95 \%$ for mean } \\
\hline & & & & & Lower & Upper \\
\hline$\overline{\mathrm{AVL}}$ & 19 & 0.2529 & 0.0052 & 8.94010 & 0.2420 & 0.2638 \\
\hline AVF & 18 & 0.2601 & 0.0056 & 9.13090 & 0.2483 & 0.2719 \\
\hline \multicolumn{7}{|l|}{ ST segment } \\
\hline LI & 10 & 0.1026 & 0.0081 & 24.8763 & 0.0843 & 0.1208 \\
\hline LII & 19 & 0.1092 & 0.0053 & 21.3549 & 0.0979 & 0.1204 \\
\hline LIII & 19 & 0.1168 & 0.006 & 22.4080 & 0.1042 & 0.1294 \\
\hline AVR & 19 & 0.1152 & 0.0068 & 25.8436 & 0.1008 & 0.1295 \\
\hline AVL & 19 & 0.1245 & 0.0054 & 18.7608 & 0.1133 & 0.1358 \\
\hline AVF & 18 & 0.1149 & 0.0054 & 19.9820 & 0.1035 & 0.1264 \\
\hline \multicolumn{7}{|l|}{$T$ wave } \\
\hline LI & 10 & 0.0761 & 0.0066 & 27.4915 & 0.0612 & 0.0911 \\
\hline LII & 19 & 0.0860 & 0.0053 & 27.0298 & 0.0748 & 0.0972 \\
\hline LIII & 19 & 0.0839 & 0.0052 & 26.8936 & 0.0730 & 0.0948 \\
\hline AVR & 19 & 0.0837 & 0.0053 & 27.5180 & 0.0726 & 0.0948 \\
\hline AVL & 19 & 0.0719 & 0.0043 & 25.8494 & 0.0630 & 0.0809 \\
\hline AVF & 18 & 0.0839 & 0.0050 & 25.3966 & 0.0733 & 0.0945 \\
\hline
\end{tabular}

variations. The scaling of AV conduction velocity (PRi) compensates for size differences, resulting in the strong similarity and optimal haemodynamic function of the heart (Meijler and Meijler, 2011). The PRi in mammals indeed vary for instance from about $0.04 \mathrm{sec}$ in mice to about 0.40 sec in elephants and whales (Noujaim et al., 2004). In SAFS, the PRi showed low variability $(7.2 \%)$ and similar to other mammals it decreased with the increase in HR. Its duration was comparable with Southern Elephant Seals (Falabella et al. 1999) but shorter than in other aquatic mammals as manatees (Siegal-Willott et al. 2006), California gray whales (Ponganis and Kooyman, 1999), Southern Sea Lions (Dassis et al., 2016) and other terrestrial mammals as the horse $(0.28 \pm 0.12 \mathrm{sec})$. In the latter, the PRi is usually long, variable and functionally prolonged by vagal influence.

The measured PRi in SAFS resulted concordant with the predicted PRi $(0.13 \pm 0.004 \mathrm{sec})$ derived from the Noujaim's allometric equation (Noujaim et al., 2004) which assumes optimal heart functioning and was established with the largest set of published ECGs (33 species, including humans). As we previously proposed for the Southern Sea Lion (Dassis et al., 2016), the good correlation between measured and predicted PRi might indicate and adequate $\mathrm{AV}$ conduction time to allow an efficient ventricular filling and a consequent efficient cardiac output. An optimal coordinated function between atrial and ventricular contraction is essential in any mammal species but even more, so, in marine mammals that must precisely adjust cardiac function during breath-hold diving in order to maximize dive duration and foraging success (Scholander, 1940; Butler and Jones, 1982, 1997; Davis, 2014). Despite, these adjustments have been traditionally associated with the dive response (cessation of breathing accompanied by a bradycardia a reduction in cardiac output and a peripheral vasoconstriction (Scholander, 1940; Butler and Jones, 1982, 1997; Davis and Kanatous, 1999; Davis and Williams, 2012), recent investigations using high resolution ECG recorders attached to weddell seals and bottlenose dolphins have suggested an even more extreme ability for cardiac regulation (Davis, 2014; Williams et al., 2015). This last include the interaction between the bradycardia associated to the dive response and the tachycardia of the exercise response (with one or the other predominating depending on the exercise level) and a significant occurrence of cardiac anomalies such us arrhythmias and ectopic beats, attributed to the interplay between sympathetic and parasympathetic drivers during dive (Williams et al., 2015). Such marked cardiac variability has changed the common view of a stereotypic dive response and have pointed out the need of further detailed studies in marine mammals cardiac biomechanics and bioelectricity.

The contractions of ventricles are preceded by their electrical activation. The QRS complex represents the ventricular depolarization (left ventricle, interventricular septum and right ventricle) (Tilley and Smith, 2008). This activation (QRS complex) is linked by a varying time interval. This interval variation depends on cardiac mass or body mass and controls the optimisation of cardiac output under all circumstances (Meijler and Meijler, 2011). In this way, even in marine mammals, the direct relationship between body mass and QRS duration seems to be maintained. The duration of the QRS complex of the SAFS $(0.070 \mathrm{sec})$ was lower than that described in other pinnipeds and marine mammals with higher body mass (for example, $0.080 \mathrm{sec}$ in SSL (Dassis et al., 2016); $0.080-0.110 \mathrm{sec}$ in manatees (Siegal-Willott et al., 2006) and $0.208 \mathrm{sec}$ in California gray whale (Ponganis and Kooyman, 1999). The ventricular activation has been classified in type A mammals (human, monkey dog, cat, 
rat) with three fronts of depolarization waves and type $B$ mammals (cow, pig, horse, sheep etc.,) with two wave fronts. This classification of ventricular activation requires the characterization of the anatomy of the cardiac conduction system. However, Siegal-Willott et al. (2006) hypothesized that manatees have a depolarization similar to that of the horse and thus, manatees should be classified as type B. This inference was based on the only existing anatomical description and the predominantly positive deflection in LI. To date, the conduction system within the SAFS heart has not yet been determined and we cannot make similar assumptions. However, mean electrical axes reflected left and cranial orientation of the mean QRS vector in most of the SAFS studied, similar to Northern elephant seals, Southern elephant seals, harbour seals, pig and horses (Hamlin et al., 1972). Based on these similarities we suggest that SAFS may have a type B ventricular activation, however, further research is needed to elucidate this issue.

The STs reflects the end of ventricular depolarization and precedes ventricular repolarization. In accordance with previous reports in SSL (Dassis et al., 2016) most of the SAFS studied showed normal STs, only two animals showed pattern of STs depression. Elevation and depression of STs in human and veterinary electrocardiography represent several disorders such as myocardial ischemia and infarction, pulmonary embolism, early repolarization, electrolyte disorders, left ventricular hypertrophy, conduction abnormalities, valvular diseases, pericardial diseases and cardiomyopathies (Tilley and Smith 2008; Hanna and Glancy, 2011, 2015). The identification of morphology of ST-segment may help veterinarians to detect some abnormalities from the observation of ECGs. Nonetheless, there was not enough evidence in this study to suggest these pathologies were present in the SAFS with ST depression. In addition, $\mathrm{T}$ waves did not exhibit abnormalities which would is also suggesting a normal ventricular repolarization. The importance of this result relies in that reversal of $\mathrm{T}$ wave polarity is most often considered abnormal and might indicate similar pathologies as those suggested by the STs depression (Bolton, 1975). Until more data is available, the STs depression could be considered an incidental finding in the SAFS ECG.

The QTi represents the time required to achieve ventricular depolarization and the time required to complete the repolarization processes (Tilley and Smith, 2008). The $Q T i$ has been a focus of attention in veterinary cardiology in the last years. Several conditions, congenital and acquired can have a direct effect on ventricular repolarization (Finley et al., 2003; Agudelo et al., 2011). The prolongation of the QTi interval has clinical importance in the inhalation anaesthesia (Baillard et al., 2000; Da Silva et al., 2002; Yildirim et al., 2004). Several studies have shown that volatile anaesthetics prolonged the QT of the ECG during inhalational induction of anaesthesia (Batcvarow and Malik, 2000; Yildirim et al., 2004). On the other hand, long-QT syndrome is similarly characterized by long QT-interval and an increased risk of sudden cardiac death (Finley et al., 2003). The length of QTi in SAFS was lower than that reported in other pinnipeds (Hamlin et al., 1972; Dassis et al., 2016), cetaceans (as dolphins and whales; Ponganis and Kooyman, 1999) and other aquatic mammals (Siegal-Willot et al., 2006). Considering that there are no previous reports of reference values of QTi specifically in SAFS it would be imprudent to make inferences about the potential effects of isoflouoran on the QTi in SAFS. However, the values of QTi and QTc obtained in this study constitute the first approximation to the reference intervals of QTi for the SAFS a value that must be compared with future electrocardiographic studies in non-sedated resting SAFS.

\section{CONCLUSION}

This study constitutes the first detailed description of the anesthetized SAFS electrocardiogram which in general resembled the typical ECG tracing of terrestrial and marine mammals and with no evident arrhythmia in any animal. All the waves, intervals and segments of the ECG were easily identified and characteristically displayed a distinctly defined STs and QTi with a T wave clearly differentiated from the QRS complex. An ST depression and a notched $\mathrm{P}$ wave were observed in few animals but both might be considered as normal findings in the SAFS ECG. Results obtained here represented novel and useful information for comparative electrophysiology analysis and have provided valuable information for health assessment and cardiac monitoring during anaesthesia in SAFS.

\section{ACKNOWLEDGEMENTS}

We thank the invaluable fieldwork assistance of DINARA personnel-Cesar Barreiro, Nelson Veiga, Leonardo Olivera, Fernando Area and Miguel Casella-during capturing and handling of the sea lions. Anaesthesia and veterinary control was performed by DMVs Eduardo Mateos and Valeria Ruoppolo. We also thank Jessica D' Imperio, Eduardo Juri, Meica Valdivia and Sabrina Riveron for their assistance in field work. We specially thank MartIn Barzizza, Biodesarrollos equipamiento mEdico (http://www.biodesarrollos- 
srl.com.ar/) and Cardiotecnica Argentina (http://www. cardiotecnica.com//) for assistant and support on the acquisition and use of the ECG equipment. Permits were issued by DINARA (Nota A/009/2006; nota 13/11/2009, Exp.1378/08). Funding for this project was provided by DINARA, Ministerio de Ganaderia, Agricultura y Pesca del Uruguay (Resolucion Ministerial 001/1383/2007; Expedientes DINARA No. 1136/2006, 503/2007 y 1378/2008), Agencia Nacional de Promocion Cientifica y Tecnologica of Argentina (Projects PICTs 2007-01763; 2011-1834; 2014-2135; 2016-0639), Universidad Nacional de Mar del Plata, Argentina (Projects 15/E471; 15/E335;15/E752; 15/E658; 15E868) and an NSF-CONICET Cooperation Grants (CONICET Resolutions 1340/10 and $0145 / 15$ ). We also thank the Society for Marine Mammalogy for providing the grant for the ECG equipment acquisition (http:/www.marinemammal science.org/).

\section{REFERENCES}

Agudelo, C.F., P. Scheer and J. Tomenendalova, 2011. How to approach the QT interval in dogs-state of the heart: A review. Vet. Med., 56: 14-21.

Andrews, R.D., D.R. Jones, J.D. Williams, P.H. Thorson and G.W. Oliver et al., 1997. Heart rates of northern elephant seals diving at sea and resting on the beach. J. Exp. Biol., 200: 2083-2095.

Anonymous, 2010. Clinical guidelines by consensus; recording a standard 12-lead electrocardiogram: An approved methodology. British Cardiovascular Society. London.

Baillard, C., P. Mansier, P.V. Ennezat, L. Mangin and C. Medigue et al., 2000. Converting enzyme inhibition normalizes QT interval in spontaneously hypertensive rats. Hypertens., 36: 350-354.

Batchvarov, V. and M. Malik, 2000. Measurement and interpretation of QT dispersion. Prog. Cardiovasc. Dis., 42: 325-344.

Bazett, H.C., 1920. An analysis of the time relations of electrocardiograms. Heart, 7: 353-370.

Bolton, G.R., 1975. Handbook of Canine Electrocardiography. W.B. Saunders Company, Philadelphia, Pennsylvania, ISBN: 9780721618388 , Pages: 370 .

Butler, P.J. and D.R. Jones, 1982. The comparative physiology of diving in vertebrates. Adv. Comp. Physiol. Biochem., 8: 179-364.

Butler, P.J. and D.R. Jones, 1997. Physiology of diving of birds and mammals. Physiol. Rev., 77: 837-899.

Carman, V.G., A. Mandiola, D. Alemany, M. Dassis and J.P.S. Pon et al., 2016. Distribution of megafaunal species in the Southwestern Atlantic: Key ecological areas and opportunities for marine conservation. ICES. J. Mar. Sci., 73: 1579-1588.
Castellini, M.A. and T. Zenteno-Savin, 1997. Heart rate scaling with body mass in pinnipeds. Mar. Mammal Sci., 13: 149-155.

Da Silva, V.J.D., E.F. Neto, H.C. Salgado and R.F. Junior, 2002. Chronic converting enzyme inhibition normalizes QT interval in aging rats. Braz. J. Med. Boil. Res., 35: 1025-1031.

Dassis, M., D.H. Rodriguez, E. Rodriguez, A.P. De Leon and E. Castro, 2016. The electrocardiogram of anaesthetized southern sea lion (Otaria flavescens) females. J. Vet. Cardiol., 18: 71-78.

Davis, R.W. and S.B. Kanatous, 1999. Convective oxygen transport and tissue oxygen consumption in Weddell seals during aerobic dives. J. Exp. Biol., 202: 1091 1113.

Davis, R.W. and T.M. Williams, 2012. The marine mammal dive response is exercise modulated to maximize aerobic dive duration. J. Comp. Physiol. A., 198: 583591.

Davis, R.W., 2014. A review of the multi-level adaptations for maximizing aerobic dive duration in marine mammals: From biochemistry to behavior. J. Comp. Physiol. B., 184: 23-53.

Detweiler, D.K., 1988. The Dog Electrocardiogram: A Critical Review. In: Comprehensive Electrocardiography: Theory and Practice in Health and Disease, Macfarlane, P.W. and T.D.V. Lawrie (Eds.). Pergamon Press, New York, USA., ISBN:9780080355689, pp: 1267-1329.

Falabella, V., C. Campagna and M. Lewis, 1999. Electrocardiography of southern elephant seal (Mirounga leonine) weanlings. J. Zoo wildl. Med., 30: 526-531.

Finley, M.R., J.D. Lillich, R.F.G. Jr and L.C. Freeman, 2003. Structural and functional basis for the long QT syndrome: Relevance to veterinary patients. J. Vet. Internal Med., 17: 473-488.

Gehrmann, J., P.E. Hammer, C.T. Maguire, H. Wakimoto and J.K. Triedman et al., 2000. Phenotypic screening for heart rate variability in the mouse. Am. J. Physiol. Heart Circulatory Physiol., 279: H733-H740.

Guimaraes, J.P., R.B. Mari, A. Le Bas and I.S. Watanabe, 2014. Adaptive morphology of the heart of SouthernFur-Seal (Arctocephalus australis-Zimmermamm, 1783). Acta Zool., 95: 239-247.

Hamlin, R.L., J.A. Himes, H. Guttridge and W. Kirkham, 1970. P wave in the electrocardiogram of the horse. Am. J. Vet. Res., 31: 1027-1031.

Hamlin, R.L., S.H. Ridgway and W.G. Gilmartin, 1972. Electrocardiogram of pinnipeds. Am. J. Vet. Res., 33: 867-875.

Hanna, E.B. and D.L. Glancy, 2011. ST-segment depression and T-wave inversion: Classification, differential diagnosis and caveats. Cleveland Clinic J. Med., 78: 404-414. 
Hanna, E.B. and D.L. Glancy, 2015. ST-segment elevation: Differential diagnosis, caveats. Cleveland Clinic J. Med., 82: 373-384.

Harms, C.A., E.D. Jensen, F.I. Townsend, L.J. Hansen and L.H. Schwacke et al., 2013. Electrocardiograms of bottlenose dolphins (Tursiops truncates) out of water: Habituated collection versus wild postcapture animals. J. Zoo Wildl. Med., 44: 972-981

Kastelein, R.A. and F.L. Meijler, 1989. Respiratory arrhythmia in the hearts of harbour porpoises (Phocoena phocoena). Aquat. Mammals, 15: 57-63.

King, R.L., J.L. Jenks Jr and P.D. White, 1953. The electrocardiogram of a beluga whale. Circulation, 8 : 387-393.

Kligfield, P., L.S. Gettes, J.J. Bailey, R. Childers and B.J. Deal et al., 2007. Recommendations for the standardization and interpretation of the electrocardiogram, part I: The electrocardiogram and its technology. J. Am. Coll. Cardiol., 49: 1109-1127.

Meijler, F.L. and L.H. Van Der Tweel, 1986. Electrocardiograms of 10 elephants and a killer whale in Harderwijk. Ned. Tijdschr. Voor Geneeskunde, 130: 2344-2348.

Meijler, F.L. and T.D. Meijler, 2011. Archetype, adaptation and the mammalian heart. Neth. Heart J., 19: 142-1 48.

Meijler, F.L., 1985. Atrioventricular conduction versus heart size from mouse to whale. J. Am. Coll. Cardiol., 5: 363-365.

Meijler, F.L., F.H. Wittkampf, K.R. Brennen, V. Baker and C. Wassenaar et al., 1992. Electrocardiogram of the humpback whale (Megaptera noaeangliae) with specific reference to atrioventricular transmission and ventricular excitation. J. Am. Coll. Cardiol., 20: 475479.

Murdaugh JR, H.V., J.C. Seabury and W.L. Mitchell, 1961. Electrocardiogram of the diving seal. Circulation Res., 9: $358-361$.

Noren, S.R., V. Cuccurullo and T.M. Williams, 2004. The development of diving bradycardia in bottlenose dolphins (Tursiops truncates). J. Comp. Physiol. B., 174: 139-147.

Noujaim, S.F., E. Lucca, V. Munoz, D. Persaud and O. Berenfeld et al., 2004. From mouse to whale: A universal scaling relation for the $\mathrm{PR}$ interval of the electrocardiogram of mammals. Circulation, 110: 28022808.

Perez, W., H. Katz and M. Lima, 2008. Gross heart anatomy of Arctocephalus australis (Zimmerman, 1783). Anat. Sci. Intl., 83: 6-10.
Ponganis, P.J. and G.L. Kooyman, 1999. Heart rate and electrocardiogram characteristics of a young california gray whale (Eschrichtius robustus). Mar. Mammal Sci., 15: 1198-1207.

Ponganis, P.J., G.L. Kooyman, L.M. Winter and L.N. Starke, 1997. Heart rate and plasma lactate responses during submerged swimming and trained diving in California sea lions, Zalophus californianus. J. Comp. Physiol. B., 167: 9-16.

SAS Software., 2011. Statistical analysis systems. SAS Institute Inc., Cary, North Carolina.

Scholander, P.F., 1940. Experimental Investigations on the Respiratory Function in Diving Mammals and Birds. I kommisjon hos Jacob Dybwad, Oslo, Norway, Pages: 131.

Senft, A.W. and J.K. Kanwisher, 1960. Cardiographic observations on a fin-back whale. Circulation Res., 8: 961-964.

Siegal-Willott, J., A. Estrada, R. Bonde, A. Wong and D.J. Estrada et al., 2006. Electrocardiography in two subspecies of manatee (Trichechus manatus latirostris and Tm manatus). J. Zoo Wildl. Med., 37: 447-453.

Tilley, L.P. and F.W.K. Smith, 2008. Electrocardiography. In: Manual of Canine and Feline Cardiology, Tilley, L.P., F.W.K. Smith Jr, M.A. Oyama and M.M. Sleeper, (Eds.). Saunders Publisher, Philadelphia, Pennsylvania, pp: 49-77.

Tilley, L.P. and L.P. Tilley, 1992. Essentials of Canine and Feline Electrocardiography: Interpretation and Treatment. 3rd Edn., Lea \& Febiger, Philadelphia, Pennsylvania, ISBN:9780812114430, Pages: 470.

Van Citters, R.L., D.L. Franklin, O.A. Smith Jr, N.W. Watson and R.W. Elsner, 1965. Cardiovascular adaptations to diving in the northern elephant seal Mirounga angustirostris. Comp. Biochem. Physiol., 16: $267-276$

Vaz-Ferreira, R., 1982. Otaria ?avescens (Shaw 1800), South American sea lion. FAO. Fish. Ser., 5: 477-496.

Williams, T.M., L.A. Fuiman, T. Kendall, P. Berry and B. Richter et al., 2015. Exercise at depth alters bradycardia and incidence of cardiac anomalies in deep-diving marine mammals. Nat. Commun., 6: 1-9.

Williams, T.M., W.A. Friedl and J.E. Haun, 1993. The physiology of bottlenose dolphins (Tursiops truncates): Heart rate, metabolic rate and plasma lactate concentration during exercise. J. Exp. Biol., 179: 31-46.

Yildirim, H., T. Adanir, A. Atay, K. Katircioglu and $\mathrm{S}$. Savaci, 2004. The effects of sevoflurane, is oflurane and desflurane on QT interval of the ECG. Eur. J. Anaesthesiology, 21: 566-570. 